\title{
Evaluate the Effect of Education Interventions in the Prevention of Diabetic Foot Ulcers through Knowledge of the Disease and Self-Care Practices in Saudi Arabia
}

\section{Nagwa Mohammad Ahmed", Reham Mohammad Khresheh}

Surgical Nursing, Department of Nursing, University College of Umulj, University Of Tabuk, Kingdom of Saudi Arabia

"Corresponding Author: Dr. Nagwa Mohammad Ahmed, Surgical Nursing, Department of Nursing, University College of Umulj, University of Tabuk, Kingdom of Saudi Arabia, E-mail: n-mohamed@ut.edu.sa

Received: 11 October 2018; Accepted: 17 October 2018; Published: 23 October 2018

\section{Abstract}

Background: Diabetes mellitus places a substantial burden on society worldwide. Diabetic foot ulcers are a challenging problem for clinicians. Seven generally accepted detriments to healing of diabetic foot ulcers were identified: infection, glycaemic control, vascular supply, smoking, nutrition and deformity.

Aim: To evaluate the effect of education interventions in the prevention of diabetic foot ulcers through knowledge of the disease and self-care practices.

Methods and design: A quasi-experimental, design used. The study conducted in the Internal Medicine Department and Outpatient clinic at Umulj general hospital -2016. The study sample consists of 60 adult patients with diabetes mellitus. Approval to conduct the study obtained from the Ministry of Health and the University of Tabuk Research Ethics Committee.

Results: This study shows that, a significant relationship between levels of patient's knowledge, practice and level of education. The result of the present study concluded that implementation of the developed educational program showed significant improvement in the patients level of knowledge, patients ability to perform self-foot care and level of patient awareness after program implementation. 
Keywords: Diabetes mellitus; Diabetic foot; Amputations; Self-care; Knowledge

\section{Introduction}

The World Health Organization (WHO) has reported that Saudi Arabia ranks the second highest in the Middle East, and is seventh in the world for the rate of diabetes. It is estimated that around 7 million of the population are diabetic and almost around 3 million have pre-diabetes. Even more worrying perhaps, is the increasing pattern of diabetes noted in Saudi Arabia in the recent past. In fact, diabetes has approximately registered a ten-fold increase in the past three eras in Saudi Arabia [1].

Diabetes mellitus is a chronic metabolic multifactorial disorder associated with altered glucose homeostasis as well as macro and microvascular complications including preventable foot problems that are common occurrences in these patients [2]. Diabetic foot problems are major causes of morbidity and premature mortality and contribute substantially to health care costs [3]. Foot ulcerations are also a major complication in diabetes patients ( 25\%) and infected diabetic foot ulcers are responsible for $60 \%$ of nontraumatic lower limb amputations Previous studies have reported that early identification of people at high risk for foot problems and management of the risk factors could prevent lower extremity amputations and foot ulcerations $[4,5]$.

Nurses can also educate patients on the importance of controlling blood glucose levels through diet. Lastly, nurses need to educate patients about prevention and treatment of diabetic foot problems. A major problem associated with diabetes is the onset of complications that may affect the patient's health status and may become life threatening [6]. Most importantly, the nurse should educate the patient to report foot problems to his or her doctor as soon as they are noticed. These problems include cuts or breaks in the skin, ingrown nails, pain or loss of sensation, and changes in the color or discoloration of the foot [7]. The aim of the study is to evaluate the effect of education interventions in the prevention of diabetic foot ulcers through knowledge of the disease and self-care practices.

\subsection{Research Hypothesis}

Knowledge and self-care practices about foot care will be better among the educational interventions group than the control group.

\subsection{Research Design}

A quasi-experimental study design was utilized.

\subsection{Setting}

The study was conducted at the Internal Medicine Department and Outpatient clinic at Umlui General Hospital. Saudi Arabia. 
1.3.1 Sample: 60 adult male and female who have type 2 diabetes mellitus were included. Patients were randomly assigned into groups: group $1(n=30)$ which was the 'intervention' group and group II $(n=30)$ which was the control group. Group '1' participants received an educational program containing the instructions and were trained on the activities included in it. While group 'II' received standard hospital care.

1.3.2 Inclusion Criteria: Patients who have type 2 diabetics mellitus, both age and gender range between 18-60 years old and duration of diabetes more than 5 years.

1.3.3 Exclusion criteria: Patients with gastroparesis, orthostatic hypotension and hypoglycemia unawareness (autonomic neuropathy). Mentally ill patients, hearing or visual difficulties. The work was performed by including the patients admitted on Sunday, Monday and Tuesday in the intervention group and the patients admitted during the rest of days the week in the control group.

1.3.4 Study tools: In order to collect the necessary information for the study, the following tools were used:

Tool I: Patient's assessment sheet includes 4 items

1. Sociodemographic data.

2. Patients' assessment related to knowledge.

3. Patients' assessment related to self-care practices.

4. Leg assessment sheet.

Tool II: A designed nursing intervention protocol includes 4 items

1. Knowledge related to diabetes and foot care.

2. Self-care practices concerning diabetes and foot care.

3. Diabetes nutrition.

4. Insulin injection

Tool III: Observational checklist related to foot care.

\section{Patient Assessment Sheet}

It was developed by the researcher to collect general information related to personal data and diabetic patient assessment. Content validity of the tool was tested by expertise in medical and nursing field. This tool is divided into four parts to cover the following dimensions: Sociodemographic data, patient assessment related to knowledge, patient assessment related to self-care practices and leg assessment sheet. These data were collected and the questionnaire sheet was filled by the researcher through, an interview, by taking a history from patients, assessment of the patient and educating them. This tool includes questions in the form of multiple choice questions and others in the form of closed questions. It compromised the following: 


\subsection{Sociodemographic data}

It include demographic characteristics of the studied groups as regarding their age, sex, marital status, occupation, level of education, duration of diabetes and residence.

\subsection{Patient assessment related to knowledge}

It was used to collect data as regarding: diabetes information which includes; what about diabetes, signs and symptoms of hyper glycemia and hypoglycemia, proper diabetic nutrition and complications of diabetes mellitus. Exercise information includes the following; proper diabetes exercise, cautions when performing exercise and types of exercise. Diabetic foot information includes the following; what about diabetic foot, causes of diabetic foot and complications of diabetic foot and proper foot care which categorized as; proper foot inspection, proper foot hygienic care, early detection of diabetic foot, trimming toe nail, proper foot wear and improving lower limp circulation.

Scoring system was rated for two levels; yes and no, each item score grade $=1$, for yes answer $=1$ and zero for no answer or wrong answer. Total system scores will be (19) grades. Those who obtained less than (60\%) were considered having unsatisfactory level. While those who obtained above than $(60 \%)$ were considered having satisfactory level of knowledge and practice. Reliability for the test tools was used to determine the extent to which the items in the questionnaire are related to each other. Cronbach's alpha model was used in the analysis; it is a model of internal consistency, a value greater than 0.8 denotes very good internal consistency meaning that the questionnaire is reliable. The results regarding our questionnaire were as follows 0.848 [8].

\subsection{Patient assessment related to self-care practices}

It was developed by expertise in medical and nursing field. Modifications were done based on review related literature, clinical learning experience of the researcher and expertise selected certain items to suite the aim of the study. Content validity of this tool was tested by expertise in medical and nursing field. This tool was used to identify patient performance related to foot care and contain certain items were selected such as: Foot inspection; use mirror to see bottoms of the feet. Proper foot cleaning includes the following; washing the feet in warm water, do not soak the feet, drying the feet well and dry between toes. Nail and foot care includes the following; lubricating the feet to keep skin soft and smooth, do not apply cream between toe fingers and trim the nail straight across and file the edge with nail file. Proper habits to protect the feet which categorized as; patient move ankle up and down for 5 minutes, put the feet up when setting position, don't sit for long period of time, don't cut corns and calluses, smooth corns and calluses gently, skin edges do not remove by himself, use proper foot wear, check color of feet and leg, wear slippers when get out of bed and continuous follow up care plan.

\subsection{Leg assessment sheet}

It was used to collect data to assess condition of the right and left leg and effect of diabetes on it. They include following categories related to foot assessment such as: Examining peripheral pulse; femoral, popliteal, posterior 
tibial and dorsalis pedis pulse. Skin leg temperature, skin turgor and skin color. Pain site, pain frequency and pain degree (pain degree measured by using numeric rating scale, a pain scale measures a patient's pain intensity or other features. Pain scales are based on self-report and rated from 0 to 10). Lower limp edema, edema type (absent, mild, moderate or severe), leg edema location; (none, localized per ulcer, foot inducing ankle, to mid-calf, or to knee), perception of pain, touch and temperature. Perception to touch assessed by using Sennses-Weinstein monofilament and general wellbeing (Satisfied and dissatisfied).

This type of data were collected thorough examination of patient legs pre protocol and after 3 month follow up post protocol, leg examination done to assess the effect of diabetes on the foot and to prevent, early detect any complications. Confirmation was done by the researcher.

\section{Tool II: A Designed Nursing Intervention Protocol Includes 4 Parts}

Content of protocol was developed by the researcher and revised by expertise in medical and nursing field, the content were consistent with related literature. This tool is divided into four parts: knowledge related to diabetes and foot care, self-care practices concerning diabetes and foot care, diabetes nutrition and insulin injection, confirmation of data was done by the researcher.

\subsection{Knowledge related to diabetes and foot care}

It was used to provide and increase patients' knowledge which includes: what about diabetes, signs and symptoms of hyperglycemia and hypoglycemia, complications of diabetes mellitus. Exercise information includes the following; proper diabetes exercise, cautions when performing exercise and types of exercise. Diabetic foot information includes the following; what about diabetic foot, causes of diabetic foot and complications of diabetic foot.

\subsection{Self-care practices concerning diabetes and foot care}

Patient self-care practices based on knowledge provided to the patient, which includes: early detection of diabetic foot ulcer thorough examining the foot, prevention of diabetic foot occurrence by performing daily basis of foot care and performing proper exercise.

\subsection{Diabetes nutrition}

This tool it was used to identify proper nutrition for patients, the content was developed based on review related literature, which includes: purpose from good nutrition, how to preparing a healthy diet, rules for proper nutrition, component of nutrition, food pyramids and examples of models of a healthy diet.

\subsection{Insulin injection}

Considering as a part of diabetes self-care that help the patient to be able to perform self-injection. This part includes: information about insulin and how to performing insulin injection. 


\section{Tool III. Observational Chick List Related to Foot Care}

It was developed by expertise on medical and nursing field. Modifications were done based on review related

literature, theoretical and clinical learning experience of the researchers and expertise selected certain items to suite the aim of the study. Content validity of this tool was tested by expertise in medical and nursing field. This tool was used to identify patient performance related to foot care and contain certain items were selected such as: Washing the feet in warm water, dry between toes, do not soak the feet, lubricating the feet to keep skin soft and smooth, do not apply cream between toe fingers, trim the nail straight across and file the edge with nail file, patient move ankle up and down for 5 minutes, put the feet up when setting position, don't sit for long period of time, check color of feet and leg, don't cut corns and calluses, smooth corns and calluses gently, skin edges do not remove by himself, use proper foot wear, wear slippers when get out of bed, use mirror to see bottoms of the feet and continuous follow up care plan. Observational chick list performed and confirmed by the researcher. Scoring system was rated for two levels; done and not done, each item was observed, categorized and scored into either done correctly=1. Don=1, not done $=0$. Total system scores for all items was (18) grades. Those who obtained less than $(60 \%)$ were considered having unsatisfactory level. While those who obtained above than $(60 \%)$ were considered having satisfactory level of practice.

\section{Procedure}

The study was carried out on 3 phases:

\subsection{The preparatory phase (first phase)}

In which the study tools and the designed teaching protocol was developed and the content were consistent with related literature (nursing text book, journal and internet source) about diabetes, foot assessment and foot care. The pilot study was to test the applicability of the assessment tools, identify how data was collected in an effective way, also to identify the possible obstacles or problem that may hinder the data collection during the implementation phase.

\subsection{Implementation phase (second phase)}

The patient assessment was conducted pre protocol, immediate post protocol and after 3 month follow up through: Asking patient questions to collect information that was related to sociodemographic data for example age, sex, occupation, level of education and duration of diabetes, patient knowledge assessment through asking questions related to diabetes and foot care as including, what about diabetes, proper diabetes care and proper foot care, foot assessment through examining both feet. Total numbers of designed protocol sessions, seven sessions divided as follows: 4 patients for each session and every 4 patients group receive all seven protocol sessions reciprocally, each session time consumed about 30 minutes due to patients interests. 
5.2.1 First session: Introduce myself to the patients (name and job), aim from meeting, number of sessions, orient the patients regarding the designed protocol contents, its purpose, related benefits and its impact on his/her condition.

5.2.2 Second session: Summary about what has been discussed in the previous sessions, objectives of the new session, content of the session includes what about diabetes mellitus, definition of diabetes mellitus, risk factors of diabetes mellitus, clinical manifestation of hypoglycemia, clinical manifestation of hyperglycemia and complications of diabetes mellitus, the session ended by a summary of its contents and feedback from the patients through health education and discussion. Many patients were cooperative with the researchers; they were very interested in the given topics and asked to continue such a training program to update their knowledge.

5.2.3 Third session: Summary about what has been discussed in the previous sessions, objectives of the new session, content of the session includes what is the diabetic foot, what are risk factors of diabetic foot ulcer and complications of diabetic foot ulcers, the session ended by a summary of its contents and feedback from the patients through discussion and asking questions.

5.2.4 Fourth session: Summary about what has been discussed in the previous sessions, objectives of the new session, content of the session includes daily foot care, toe nail care, foot wear and socks, follow up care plan, the session ended by a summary of its contents and feedback from the patients through discussion and asking questions.

5.2.5 Fifth session: Summary about what has been discussed in the previous sessions, objectives of the new session, content of the session includes purpose of nutritional planning, preparing a healthy integrated meal, general rules of dieting correctly, quality of food that suited the diabetics, times of diet, food pyramids for diabetics, models of the integrated food meals and types of food permitted without reservation, the session ended by a summary of its contents and feedback from the patients through discussion and raising of questions.

5.2.6 Sixth session: Summary about what has been discussed in the previous sessions, objectives of the new session, content of the session includes information about insulin, how to perform insulin injection and sites of insulin injection, the session ended by a summary of its contents and feedback from the patients through discussion and asking questions.

5.2.7 Last session includes: Summary about what has been discussed in the previous sessions, objectives of the new session, content of the session includes the importance of physical exercise for diabetics, what must be done when performing physical exercise, types of physical exercise and importance of physical exercise, the session ended by a summary of designed protocol contents and feedback from the patients through discussion and asking questions. 
5.2.7.1 Evaluation phase (third phase): Effect of the designed protocol on patient condition was done through comparing the pre and post assessment of the patients including: Their knowledge, ability to foot self-care and follow up regularly.

5.2.7.2 Ethical consideration: The study approved by an institutional ethics committee, informed written consent was obtained from patients who are willing to participate in the study after the nature and purpose of the study were explained. The researchers initially introduced themselves to all patients and they assured data confidentially. They were informed that their participation was voluntary and they have the right to withdraw any time from the study.

5.2.7.3 Statistical Analysis: Data entry and statistical analysis were done using SPSSver.23statical software package. Data were presented using descriptive statistics in the form of frequencies and percentage for qualitative variables mean and standard deviations for the quantities variables the level of significance was set at $(\mathrm{p}=0.05)$ to detect any indication of differences found in the data available.

\section{Result}

Table 1 shows that the majority of the study and control groups were females (63.3\%, 53.3\% respectively), and common age group category ranged from 50-59 years, regarding duration of diabetes more than half of patients were affected between 5-10 years. The majorities of the patients in study were not working $(73.3 \%, 60 \%$ respectively) and lives in urban $(76.7 \%, 80 \%$ respectively). Regarding social status the majority of them were married in both groups. (Study and Control) $(96.7 \%, 90 \%$ respectively).

\begin{tabular}{|c|c|c|c|c|c|c|}
\hline \multirow{2}{*}{$\begin{array}{l}\text { Socio-demographic } \\
\text { characteristics }\end{array}$} & \multicolumn{2}{|c|}{ Study group } & \multicolumn{2}{|c|}{ Control group } & \multirow{2}{*}{ t-value } & \multirow{2}{*}{ P-value } \\
\hline & No & $\%$ & No & $\%$ & & \\
\hline Age in years: & & 6.7 & 2 & 6.7 & \multirow{6}{*}{-0.03} & \multirow{6}{*}{0.976} \\
\hline $20-29$ & 2 & 3.3 & 1 & 3.3 & & \\
\hline $30-39$ & 1 & 30 & 11 & 36.7 & & \\
\hline $40-49$ & 9 & 60 & 16 & 53.3 & & \\
\hline $50-59$ & 18 & & & & & \\
\hline$($ Mean \pm SD) & \multicolumn{2}{|c|}{$48.4 \pm 8.8$} & \multicolumn{2}{|c|}{$48.5 \pm 8.2$} & & \\
\hline \multicolumn{6}{|l|}{ Duration of diabetes: } & \multirow{5}{*}{0.141} \\
\hline 5- 10 years & 16 & 53.3 & 22 & 73.3 & 2.37 & \\
\hline 11- 15 years & 9 & 30 & 6 & 20 & & \\
\hline Above 15 years & 5 & 16.7 & 2 & 6.7 & & \\
\hline$($ Mean \pm SD) & \multicolumn{2}{|c|}{$11.2 \pm 4.5$} & \multicolumn{2}{|c|}{$8.6 \pm 2.5$} & & \\
\hline & No & $\%$ & No & $\%$ & $x^{2}$-value & P-value \\
\hline Gender: & & & & & 0.617 & 0.432 \\
\hline
\end{tabular}




\begin{tabular}{|c|c|c|c|c|c|c|}
\hline Male & 11 & 36.7 & 14 & 46.753 .3 & & \\
\hline Female & 19 & 63.3 & 16 & & & \\
\hline Social status: & & & & & \multirow{5}{*}{4.071} & \multirow{5}{*}{0.254} \\
\hline Single & 1 & 3.3 & 0 & 0 & & \\
\hline Married & 29 & 96.7 & 27 & 90 & & \\
\hline Divorced & 0 & 0 & 1 & 3.3 & & \\
\hline Widow & 0 & 0 & 2 & 6.7 & & \\
\hline \multicolumn{5}{|c|}{ Level of education: } & \multirow{5}{*}{3.468} & \multirow{5}{*}{0.325} \\
\hline Illiterate & 9 & 30 & 6 & 20 & & \\
\hline Read \& write & 7 & 23.3 & 11 & 36.7 & & \\
\hline Basic education & 10 & 33.3 & 12 & 40 & & \\
\hline University & 4 & 13.3 & 1 & 3.3 & & \\
\hline \multicolumn{5}{|l|}{ Occupation: } & \multirow{4}{*}{2.266} & \multirow{4}{*}{0.322} \\
\hline Employee & 1 & 3.3 & 4 & 13.3 & & \\
\hline Worker & 7 & 23.3 & 8 & 26.7 & & \\
\hline No work & 22 & 73.3 & 18 & 60 & & \\
\hline \multicolumn{5}{|l|}{ Residence: } & \multirow{3}{*}{0.096} & \multirow{3}{*}{0.757} \\
\hline Urban & 23 & 76.7 & 24 & 80 & & \\
\hline Rural & 7 & 23.3 & 6 & 20 & & \\
\hline
\end{tabular}

*: Significant at $\mathrm{P} \leq 0.05$

Table 1: Socio-demographic characteristics distribution of the study and control groups.

Table 2 shows the study group indicates a significant higher score in knowledge than the control group in both immediate post protocol and at follow up $(\mathrm{P}<0.001 *)$. While this table also enumerates no statistically significant difference between the study and control groups pre protocol (P- 0.155).

\begin{tabular}{|l|l|l|l|}
\hline \multirow{2}{*}{ Patients knowledge } & Study group & Control group & \multirow{2}{*}{ P-value } \\
\cline { 2 - 3 } & Mean \pm SD & Mean \pm SD & \\
\hline 1-Diabetes knowledge: & & & \\
\hline Pre protocol & $0.57 \pm 0.32$ & $0.67 \pm 0.24$ & 0.203 \\
\hline 3 mmediate post protocol & $0.97 \pm 0.09$ & $0.67 \pm 0.24$ & $<0.001^{*}$ \\
\hline 2-Importance of exercise: & $0.91 \pm 0.12$ & $0.7 \pm 0.23$ & $<0.001^{*}$ \\
\hline Pre protocol & & & \\
\hline Immediate post protocol & $0.06 \pm 0.12$ & $0.21 \pm 0.25$ & $0.004^{*}$ \\
\hline 3 month follow up & $0.76 \pm 0.25$ & $0.21 \pm 0.25$ & $<0.001^{*}$ \\
\hline 3-Diabeticfoot knowledge: & $0.60 \pm 0.49$ & $0.17 \pm 0.38$ & $<0.001^{*}$ \\
\hline Pre protocol & & & \\
\hline Immediate post protocol & $0.18 \pm 0.2$ & $0.32 \pm 0.2$ & $0.013^{*}$ \\
\hline 3 month follow up & $0.78 \pm 0.18$ & $0.32 \pm 0.2$ & $<0.001^{*}$ \\
\hline 4- Foot care knowledge: & $0.63 \pm 0.2$ & $0.35 \pm 0.2$ & $<0.001^{*}$ \\
\hline
\end{tabular}




\begin{tabular}{|l|l|l|l|} 
Pre protocol & $0.18 \pm 0.17$ & $0.25 \pm 0.2$ & 0.148 \\
\hline Immediate post protocol & $0.96 \pm 0.06$ & $0.25 \pm 0.2$ & $<0.001^{*}$ \\
\hline 3 month follow up & $0.87 \pm 0.1$ & $0.27 \pm 0.19$ & $<0.001^{*}$ \\
\hline Total mean score: & & & \\
\hline Pre protocol & $0.25 \pm 0.14$ & $0.36 \pm 0.18$ & 0.155 \\
\hline Immediate post protocol & $0.87 \pm 0.36$ & $0.36 \pm 0.18$ & $<0.001^{*}$ \\
\hline 3 month follow up & $0.75 \pm 0.27$ & $0.37 \pm 0.24$ & $* 0.001<$ \\
\hline
\end{tabular}

*: Significant at $\mathrm{P} \leq 0.05$

Table 2: Total and subtotal mean knowledge scores obtained by patient's pre, immediately and 3 month after protocol implementation.

\begin{tabular}{|l|l|l|l|l|}
\hline \multirow{2}{*}{$\begin{array}{l}\text { Patient practice related to self }- \\
\text { care practices }\end{array}$} & Study group & Control group & \multirow{2}{*}{ t-value } & \multirow{2}{*}{ P-value } \\
\cline { 2 - 5 } & Mean \pm SD & Mean \pm SD & & \\
\hline Pre protocol & $0.37 \pm 0.22$ & $0.29 \pm 0.19$ & 1.522 & 0.133 \\
\hline Immediate post protocol & $0.79 \pm 0.13$ & $0.29 \pm 0.19$ & 11.836 & $<0.001^{*}$ \\
\hline 3 month follow up & $0.76 \pm 0.1$ & $0.38 \pm 0.19$ & 9.509 & $<0.001^{*}$ \\
\hline
\end{tabular}

Table 3: Total mean practice scores for patient self-care practices related to foot care thorough out program phases among the study and control groups.

Table 3 shows that, the study group results is significantly different from the control group in both immediate post protocol and at follow up $\left(\mathrm{P}<0.001^{*}\right)$. Also this table shows no statistically significant difference between the study and control group pre protocol (P 0.133).

\begin{tabular}{|l|l|l|l|}
\hline \multirow{2}{*}{ Items } & Level of patients knowledge & Level of patient practice & \multirow{2}{*}{ P-value } \\
\cline { 2 - 4 } & Mean \pm SD & Mean \pm SD & \\
\hline Pre protocol & $0.25 \pm 0.14$ & $0.37 \pm 0.22$ & 0.097 \\
\hline Immediate post protocol & $0.87 \pm 0.36$ & $0.79 \pm 0.13$ & 0.758 \\
\hline 3 month follow up & $0.75 \pm 0.27$ & $0.76 \pm 0.1$ & 0.896 \\
\hline
\end{tabular}

Table 4: Comparison between mean score of total knowledge and practice in the study group.

Table 4 shows that there was no significant different between level of patient's knowledge and level of patients practice pre protocol, immediate post protocol and at follow up (P 0.097, 0.758, 0.896 respectively). 


\begin{tabular}{|c|c|c|c|c|c|c|c|c|c|c|c|}
\hline \multirow{3}{*}{ Leg assessment } & & \multicolumn{4}{|c|}{ Study group } & \multicolumn{4}{|c|}{ Control group } & \multirow{3}{*}{$\begin{array}{l}x^{2}- \\
\text { value }\end{array}$} & \multirow{3}{*}{$\begin{array}{l}\text { P- } \\
\text { value }\end{array}$} \\
\hline & & \multicolumn{2}{|c|}{ Pre protocol } & \multicolumn{2}{|c|}{$\begin{array}{l}\text { Follow up } \\
\text { after } 3 \text { month }\end{array}$} & \multicolumn{2}{|c|}{$\begin{array}{l}\text { Pre } \\
\text { protocol }\end{array}$} & \multicolumn{2}{|c|}{$\begin{array}{lr}\text { Follow } & \text { up } \\
\text { after } & 3 \\
\text { month } & \end{array}$} & & \\
\hline & & No & $\%$ & No & $\%$ & No & $\%$ & No & $\%$ & & \\
\hline \multirow{3}{*}{ Femoral pulse } & Diminished & 4 & 13.3 & 7 & 23.3 & 11 & 36.7 & 9 & 30 & & \\
\hline & Normal & 25 & 83.3 & 22 & 73.3 & 19 & 63.3 & 20 & 66.7 & 3.65 & 0.723 \\
\hline & Bounding & 1 & 3.3 & 1 & 3.3 & 0 & 0 & 1 & 3.3 & & \\
\hline \multirow{3}{*}{$\begin{array}{l}\text { Posterior tabial } \\
\text { pulse }\end{array}$} & Diminished & 5 & 16.7 & 4 & 13.3 & 9 & 30 & 10 & 33.3 & & \\
\hline & Normal & 24 & 80 & 25 & 83.3 & 21 & 70 & 19 & 63.3 & 5.74 & 0.452 \\
\hline & Bounding & 1 & 3.3 & 1 & 3.3 & 0 & 0 & 1 & 3.3 & & \\
\hline \multirow{2}{*}{$\begin{array}{l}\text { Dorsalis pedis } \\
\text { pulse }\end{array}$} & Diminished & 6 & 20 & 3 & 10 & 10 & 33.3 & 11 & 36.7 & & \\
\hline & Normal & 24 & 80 & 27 & 90 & 20 & 66.7 & 19 & 63.3 & 7.29 & 0.063 \\
\hline \multirow{2}{*}{ Popliteal pulse } & Diminished & 6 & 20 & 9 & 30 & 9 & 30 & 10 & 33.3 & & \\
\hline & Normal & 24 & 80 & 21 & 70 & 21 & 70 & 20 & 66.7 & 1.44 & 0.696 \\
\hline \multirow{2}{*}{ Leg temperature } & Cool & 4 & 13.3 & 6 & 20 & 3 & 10 & 3 & 10 & & \\
\hline & Normal & 26 & 86.7 & 24 & 80 & 27 & 90 & 27 & 90 & 1.73 & 0.942 \\
\hline \multirow{3}{*}{ Skin turgor } & Dry & 6 & 20 & 2 & 6.7 & 5 & 16.7 & 7 & 23.3 & & \\
\hline & Soft & 21 & 70 & 25 & 83.3 & 24 & 80 & 23 & 76.7 & 7.53 & 0.274 \\
\hline & Normal & 3 & 10 & 3 & 10 & 1 & 3.3 & 0 & 0 & & \\
\hline \multirow{3}{*}{ Skin color } & Pallor & 7 & 23.3 & 9 & 30 & 4 & 13.3 & 7 & 23.3 & & \\
\hline & Cyanosis & 3 & 10 & 4 & 13.3 & 2 & 6.7 & 0 & 0 & 7.16 & 0.306 \\
\hline & Normal & 20 & 66.7 & 17 & 56.7 & 24 & 80 & 23 & 76.7 & & \\
\hline
\end{tabular}

*: Significant at $\mathrm{P} \leq 0.05$

Table 5: Frequency and percentages of leg assessment related to pulse and skin assessment of the study and control groups.

Table 5 reveals that, number of patients suffer from diminished pulse was $13.3 \%$ - $36.7 \%$ while $63.3 \%$ to $83.3 \%$ were normal pulse. Regarding skin assessment 10\%-20\% show cold skin turgor and showed minimal improvement in follow up than pre protocol for the study group while in control group dry skin turgor increased in follow up than pre protocol. As regard to skin color, $56.7 \%$ to $80 \%$ have red skin color. 


\begin{tabular}{|c|c|c|c|c|c|c|c|c|c|c|c|}
\hline \multirow{3}{*}{ Leg assessment } & & \multicolumn{4}{|c|}{ Study group } & \multicolumn{4}{|c|}{ Control group } & \multirow{3}{*}{$\begin{array}{l}x^{2}- \\
\text { value }\end{array}$} & \multirow{3}{*}{$\begin{array}{l}\text { P- } \\
\text { valu } \\
\text { e }\end{array}$} \\
\hline & & \multicolumn{2}{|c|}{$\begin{array}{l}\text { Pre } \\
\text { protocol }\end{array}$} & \multicolumn{2}{|c|}{$\begin{array}{l}\text { Follow up } \\
\text { after } 3 \\
\text { month }\end{array}$} & \multicolumn{2}{|c|}{$\begin{array}{l}\text { Pre } \\
\text { protocol }\end{array}$} & \multicolumn{2}{|c|}{\begin{tabular}{|l|} 
Follow up \\
after 3 \\
month \\
\end{tabular}} & & \\
\hline & & No & $\%$ & No & $\%$ & No & $\%$ & No & $\%$ & & \\
\hline \multirow{4}{*}{ Pain site } & Absent & 14 & 46.7 & 13 & 43.3 & 14 & 46.7 & 11 & 36.7 & & \\
\hline & Foot & 5 & 16.7 & 4 & 13.3 & 2 & 6.7 & 3 & 10 & 6.74 & 0.664 \\
\hline & Foot $\&$ calf & 4 & 13.3 & 5 & 16.7 & 2 & 6.7 & 2 & 6.7 & & \\
\hline & Foot, calf \& thigh & 7 & 23.3 & 8 & 26.7 & 12 & 40 & 14 & 46.7 & & \\
\hline \multirow{4}{*}{ Pain degree } & Absent & 14 & 46.7 & 14 & 46.7 & 14 & 46.7 & 10 & 33.3 & & \\
\hline & Mild & 14 & 46.7 & 14 & 46.7 & 16 & 53.3 & 16 & 53.3 & 6 & 0.739 \\
\hline & Moderate & 1 & 3.3 & 1 & 3.3 & 0 & 0 & 3 & 10 & & \\
\hline & Severe & 1 & 3.3 & 1 & 3.3 & 0 & 0 & 1 & 3.3 & & \\
\hline \multirow{5}{*}{ Pain frequency } & None & 14 & 46.7 & 17 & 56.7 & 14 & 46.7 & 14 & 46.7 & & \\
\hline & Occasional & 5 & 16.7 & 3 & 10 & 2 & 6.7 & 2 & 6.7 & 6.8 & 0.87 \\
\hline & Position dependent & 6 & 20 & 6 & 20 & 10 & 33.3 & 10 & 33.3 & & \\
\hline & Constant & 4 & 13.3 & 3 & 10 & 4 & 13.3 & 4 & 13.3 & & \\
\hline & Disturbs sleep & 1 & 3.3 & 1 & 3.3 & 0 & 0 & 0 & 0 & & \\
\hline \multirow{3}{*}{$\begin{array}{l}\text { Edema type } \\
\text { and location }\end{array}$} & Absent & 28 & 93.3 & 27 & 90 & 27 & 90 & 25 & 83.3 & & \\
\hline & Mild (foot to mid-calf) & 0 & 0 & 1 & 3.3 & 3 & 10 & 4 & 13.3 & 7.37 & 0.288 \\
\hline & Severe reach the knee & 2 & 6.7 & 2 & 6.7 & 0 & 0 & 1 & 3.3 & & \\
\hline \multirow{4}{*}{$\begin{array}{l}\text { Perception to } \\
\text { touch, } \\
\text { temperature } \\
\text { and pain }\end{array}$} & Absent & 3 & 10 & 2 & 6.7 & 0 & 0 & 1 & 3.3 & & \\
\hline & Decreased & 13 & 43.3 & 13 & 43.3 & 13 & 43.3 & 11 & 36.7 & 7.61 & 0.574 \\
\hline & Increased & 0 & 0 & 1 & 3.3 & 1 & 3.3 & 3 & 10 & & \\
\hline & Normal & 14 & 46.7 & 14 & 46.7 & 16 & 53.3 & 15 & 50 & & \\
\hline
\end{tabular}

Table 6: Frequency and percentages distribution of leg assessment related to pain, edema and perception among the study and control groups.

Table 6 shows that the study and control group were identical in leg assessment pre protocol and in follow up. Regarding pain assessment nearly about half of patients with no pain, 46\%-53.3\% with mild pain, and 20\%-33.3\% pain increase with position dependent. Regarding edema assessment, $83.3 \%$ to $93.3 \%$ was normal, regarding perception $36.7 \%$ to $43.3 \%$ with decreased perception.

\begin{tabular}{|l|l|l|l|l|}
\hline \multirow{2}{*}{ Right leg } & \multicolumn{2}{|l|}{ Study group } & \multicolumn{2}{l|}{ Control group } \\
\cline { 2 - 5 } & Correlation coefficient $(\mathbf{r})$ & P-value & Correlation coefficient $(\mathbf{r})$ & P-value \\
\hline Left leg & -0.477 & $0.016^{*}$ & -0.057 & 0.802 \\
\hline
\end{tabular}

*: Significant at $\mathrm{P} \leq 0.05$

Table 7: Correlation between duration of diabetes and leg perception to pain of the study and control groups. 
In table 7 According to the Study group results is there is a statistically positive significant correlation between duration of diabetes and perception of pain as increased duration of diabetes was associated with decreased perception of pain in right and left legs (P- 0.016* $0.005^{*}$ respectively). In the Control group, there was no statistically significant correlation between duration of diabetes and perception of pain in both legs.

Figure 1 shows satisfactory level increase at follow up of the study group while decrease of the control group $(66.7 \%, 46.7 \%)$ respectively. Figure 2 shows direct positive correlation between level of patient's knowledge and level of patient's education. Figure 3 shows direct positive correlation between level of patient's knowledge and level of patient's education.

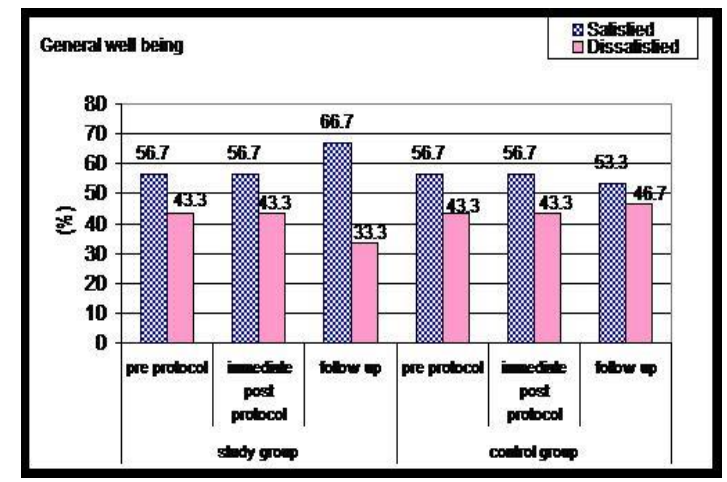

Figure 1: Satisfactory level of general well-being among the study and control groups.

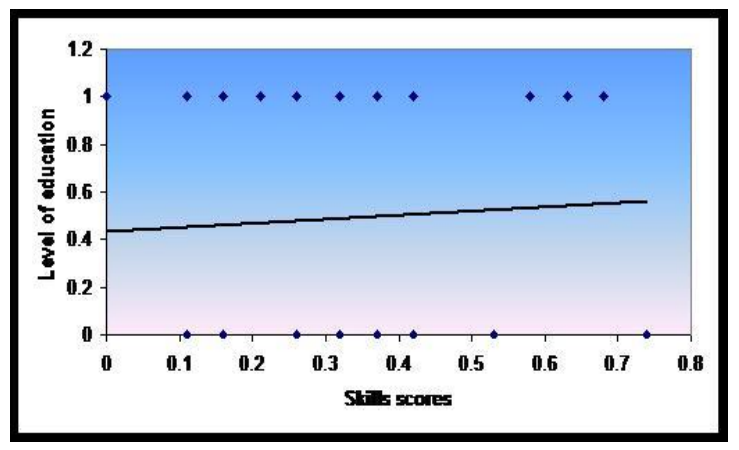

Figure 2: Correlation between level of patient's practice and level of education.

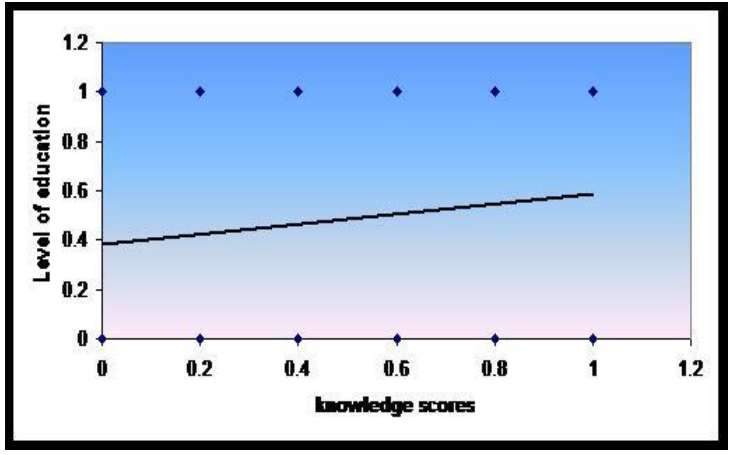

Figure 3: Correlation between level of patient's knowledge and level of education. 


\section{Discussion}

The purposes of this study were carried out to evaluate the effect of education interventions in the prevention of diabetic foot ulcers through knowledge of the disease and self-care practices. Regarding age the results indicate that more than half of patients included in this study were between $50-59$ years; $(60 \%, 53.3 \%)$ for study and control groups respectively, this finding is similar to the results of Joe et al. [9], which stated that the major categories of patients with diabetes were older people. Also this result agrees with Liudmila et al. [10] which stated that the prevalence of diabetes increase among people between 45 and 64 years old. Moreover, it has also been reported that this percentage increases significantly among older individuals. As regarding gender the majority of these study were female $(63.3 \%, 53.3 \%)$ for study and control groups respectively. Results based on this study cannot provide a definite line that the female were affected more than male. This result agrees with Liudmila et al. [10] who stated that the most patient included in their study were women.

The present study reveals that regarding social status table 1 shows that most of patients included in the present study were married $96.7 \%$, 90\% in both groups (study and control ). This result agrees with Liudmila et al. [10] which stated that most patients were observed in the study were married. Mary et al. [11] stated that no evidence is found for the hypothesis that marriage positively associated with the prevalence of diabetes. Focusing on occupation nearly about two-third of patients with no work $73.3 \%, 60 \%$, one quarter of patients were working $23.3 \%, 26.7 \%$ (driver, mechanical, circuit or plumber) these types of work might expose patients to higher risk of foot trauma especially with prolonged standing during work. This result was supported by Makota [12] that the type of occupation can produce adverse effect on diabetic rather than non-diabetics.

As regarding residence this study showed that most of patients included in the study live in urban $76.7 \%$, $80 \%$ based on finding of the study there was no significant relation between the two groups (study and control), this finding was also supported by Arch et al. [13] results which stated that $88 \%$ of patients live in urban. The study and control groups (Table 2) showed that there was a statistically significant improvement in patient's knowledge as regard to the items related to diabetes knowledge, importance of exercise, diabetic foot knowledge and foot care knowledge improved after protocol implementation among the study group $(>0.001 *)$. Control group in the assessment phase and in the follow up phase shows no statistically significant change in their knowledge, this result was supported by Abd Elateef et al. [14] they stated that implementing of intervention protocol had great effect in the improvement of patient's knowledge.

Regarding level of patient practices there a was recognized improvement immediate post protocol and at follow up in the study group compared to the control group $(\mathrm{p}->0.001 *)$, pretest compared with the posttest show improvement in the level of patient practices $38.4 \%$ to $79.5 \%$ while compared pretest with follow up test showed slightly decreased in patient practices $38.4 \%$ to $75.8 \%$. This finding agrees with Mohamed [15] study which stated that patient's level of practice improved after program implementation and slightly decreased at follow up. So continuing patient education is an important key on prevention of foot complications. Also this result was supported by Abd 
Elateef, et al. [14] they indicated that implementing of intervention protocol had great effect in improving patient practices.

As regarding to patient's leg assessment the study shows that in both groups (Study and Control) were almost identical of leg assessment prior implementing intervention protocol but shows minimal differences of leg assessment after implementing intervention protocol of the study and control groups. This finding was supported also by John (2009) who stated that no difference of leg assessment in his study. Focusing on general well being, more than half of patients in both groups with satisfactory quality of life through out the program of the study $66.7 \%, 53.3 \%$ because all patients included in this study free from foot ulcer. This finding disagrees with John (2009) which stated that, foot ulcers have a significant impact on quality of life because the patient in the study with diabetic foot ulcer. For example, the loss of mobility associated with foot ulcers affects patients' ability to perform simple, everyday tasks and to participate in leisure activities, these consequences often lead to depression and poor quality of life. Concerning relationship between level of patients practice, level of patient's knowledge and age, there were no statistically significant differences. This finding contradicts with Byron et al. [16] which stated that the older people have low levels of care for example; older people have been shown to have difficulty in undertaking basic foot-care behaviors such as inspection and appropriate nail care.

As regarding relation between duration of diabetes and level of patients knowledge, the study found that no association between duration of diabetes and level of patient knowledge (p- 0.759) this finding contradicts with Vanden et al. [17] which stated that presence of positive association between duration of diabetes and level of patient's knowledge.

\section{Conclusions}

Providing structure program for patient who has type 2 diabetes mellitus was effective in improving $t$ in the level of patients' knowledge and patients' ability to perform self-care practice.

\section{Recommendations}

Publication of booklets and dissemination among patients with type 2 diabetes mellitus on a larger probability sample is recommended.

\section{Acknowledgement}

The authors would like to acknowledge financial support for this work, from the Deanship of Scientific Research (DSR), University of Tabuk, Saudi Arabia, under grant No.0007-1438-S. We would like to thank people without whom this work would not have been possible. We would like to extend our appreciation to Saudi women who participated in the study. Their inputs generated valuable data, which can be used to improve women health care in Saudi Arabia. We wish to record our gratitude to Umulj General Hospital for their support during the period of the 
study. Also, we want to acknowledge the Umluj University College and Ministry of Health in Saudi Arabia for approving the study.

\section{References}

1. Al-Nozha MM, Al-Maatouq MA, Al-Mazrou YY, et al. Diabetes mellitus in Saudi Arabia. Saudi Med J. 25 (2008): 1603-1610.

2. International Diabetes Federation. Diabetes Atlas. (5th Edn) IDF Publications; Brussels, Belgium. The Global Burden of Diabetes (2011): 7-13.

3. Aguiree Florencia, Brown Alex, Cho Nam Ho, et al. IDF Diabetes Atlas: sixth edition. 6th ed. International Diabetes Federation; Basel, Switzerland (2013).

4. Alqurashi Khalid A, Aljabri Khalid S, Bokhari Samia A. Prevalence of diabetes mellitus in a Saudi community. Ann Saudi Med 31 (2011): 19-23.

5. Alhowaish Abdulkarim K. Economic costs of diabetes in Saudi Arabia. J Fam Community Med 20 (2013): $1-7$.

6. Bean A. Patient refusal of nutrition and hydration, the complete guide to sports nutrition. A \& $\mathrm{C}$ black publishers. American journal hospice and palliative care (2008): 81-83.

7. Bloomgarden ZT. Consequences of diabetes: cardiovascular disease, diabetes care 27 (2004): 1825-1831.

8. Revelle W, Zinbarg R. Coefficients Alpha, Beta, Omega, and the glb: Comments on Sijtsma. Psychometrika 74 (2009): 145-154.

9. Joe V. Sex distributions in control and treatment of modifiable disease risk factors among patient with diabetes, diabetes care 31 (2009): 69-74.

10. Liudmila MO, Maria LZ, Carla R. Sociodemographic and clinical characteristics of a diabetic population at a primary level health care center. Annual meeting 7 (2008): 14-18.

11. Mary P, Thomson JP, Paul MF. Threshold for detection of diabetic peripheral sensory neuropathy using a range of research grade monofilaments in persons with type 2 diabetes mellitus (2008).

12. McCarter RJ, Hempe JM, Gomez R, et al. Biological variation in predicts of retinopathy and neuropathy in type 2 diabetes 27 (2009): 1259-1264.

13. Arch G, Koopman RJ, Gill JM, et al. Relationship between continuity of care and diabetes control: evidence from the third national health and nutrition examination surgery 194 (2008): 66-70.

14. Abd-Elateef ZME, Mahmoud ST. Prevention of diabetic foot complication: Impact of implementing a designed nursing intervention protocol. Med. J. Cairo Univ 27 (2008): 59-67.

15. Mohamed MA. Improving quality of life in rheumatoid arthritis patients, faculty of nursing, Zgazig University (2008): 100-117.

16. Eberhart MS, Ogden C, Engelgau M, et al. Prevalence of overweight and obesity among adults with diagnosed diabetes, morbidity and mortality weekly report (centers for disease control and prevention) 53 (2009): 1066-1068. 
17. Van den A, Stolk RP, Rutten GE. Education integrated into structured general practice care for type 2 diabetic patients' results in sustained improvement of disease knowledge and self-care: diabetic medicine 17 (2010): 190-197.

Citation: Nagwa Mohammad Ahmed, Reham Mohammad Khresheh. Evaluate the Effect of Education Interventions in the Prevention of Diabetic Foot Ulcers through Knowledge of the Disease and Self-Care Practices in Saudi Arabia. Archives of Clinical and Medical Case Reports 2 (2018): 140-156.

(C) (1) ${ }_{\text {BY }}^{\text {This article is an open access article distributed under the terms and conditions of the }}$ 